
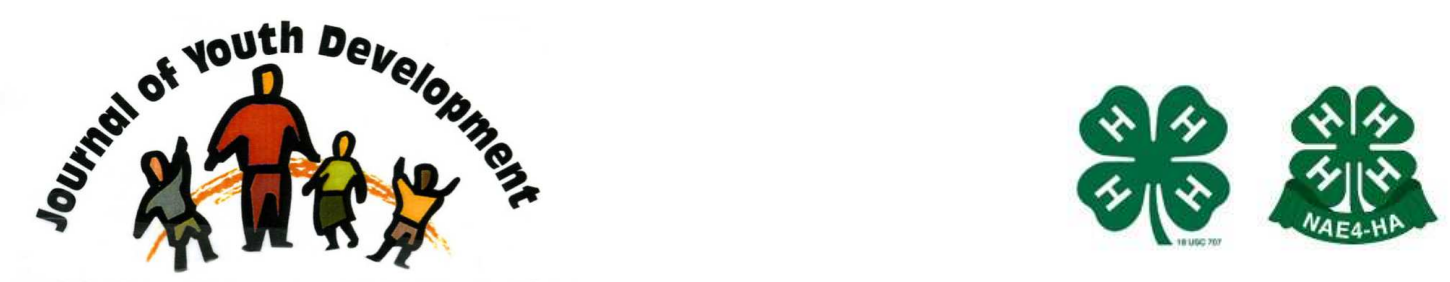

Bridging Research \& Practice

\title{
Culturally Authentic Scaling Approach: A Multi-Step Method for Culturally Adapting Measures for Use with Ethnic Minority and Immigrant Youths
}

\author{
Guerda Nicolas \\ University of Miami \\ Coral Gables, FL \\ nguerda@miami.edu \\ Angela M. DeSilva \\ Boston College \\ Chestnut Hill, MA \\ Sharon Houlahan \\ Boston College \\ Chestnut Hill, MA \\ Clelia Beltrame \\ Boston University
}




\title{
JOURNAL OF YOUTH DEVELOPMENT \\ bridging research and practice

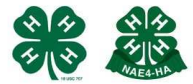

Volume4, Number 1, Spring 2009

Article 090401FA006

\section{Culturally Authentic Scaling Approach: A Multi-Step Method for Culturally Adapting Measures for Use with Ethnic Minority and Immigrant Youths}

\author{
Guerda Nicolas \\ University of Miami \\ Angela M. DeSilva, Sharon Houlahan and Clelia Beltrame \\ Boston College
}

\begin{abstract}
Given the increasing ethnic and racial diversity of youths in the U.S., researchers must be conscious of how youth are being recruited, retained, and assessed in research programs. In this article, we describe an efficient and replicable methodology, the Culturally Authentic Scaling Approach (CASA), which can be implemented to culturally adapt measures for use with ethnic minority and immigrant youths. Specifically, the steps involved in the CASA method are described, including developing community partnership, evaluating the theoretical equivalence, adjusting the selection and administration of measures. Engaging in an on-going dialogue with the community to increase cultural validity and build community relationships is also discussed. Addressing the cultural validity of measures used with ethnic and immigrant youths enhances the probability that the information obtained will be reflective of the cultural background of the participants and an accurate assessment of their experiences.
\end{abstract}

\section{Introduction}

Research on ethnic minority and immigrant populations requires instrumentation that is relevant to culture and sensitive to context (Canino \& Bravo, 1994). Recent evidence illustrates that research strategies and instruments are most efficacious when compatible with the cultural patterns and experiences of the research participants (Canino \& Bravo, 1994; Mezzich et al., 1999). 
Researchers have historically utilized methodologies and scales based on the assumptions of the mainstream American culture and not the specific cultural group being researched (Alegria et al., 2004). When standardized instruments from mainstream American culture are used with diverse cultural and ethnic groups, there is a risk that the instruments may lack cultural relevance, leading to measurement errors and misinterpretation of findings (Helms, 2006). Despite these findings, most researchers still do not modify research measures to make them more culturally relevant (Nagayama Hall, 2001). This paper provides a review of the development of the Culturally Authentic Scaling Approach (CASA), with a step by step guide (using research examples) on how to use the CASA method to conduct more culturally relevant and equivalent research.

\section{The Development of the Culturally Authentic Scaling Approach (CASA) Method}

The CASA method for conducting culturally appropriate research with ethnically diverse and immigrant groups integrates existing research literature (measurement and cross-cultural research) with ethnic minority and immigrant populations. In addition, the method applies principles from our experiences conducting cross-cultural research with ethnic minority and immigrant groups over the past fifteen years. The method is based on the integration of general cultural adaptation concepts with methodological steps that guide the process of evaluating the cultural sensitivity and appropriateness of measures for use with ethnic minority and immigrant groups.

Figure 1

Model of the Culturally Authentic Scaling Approach

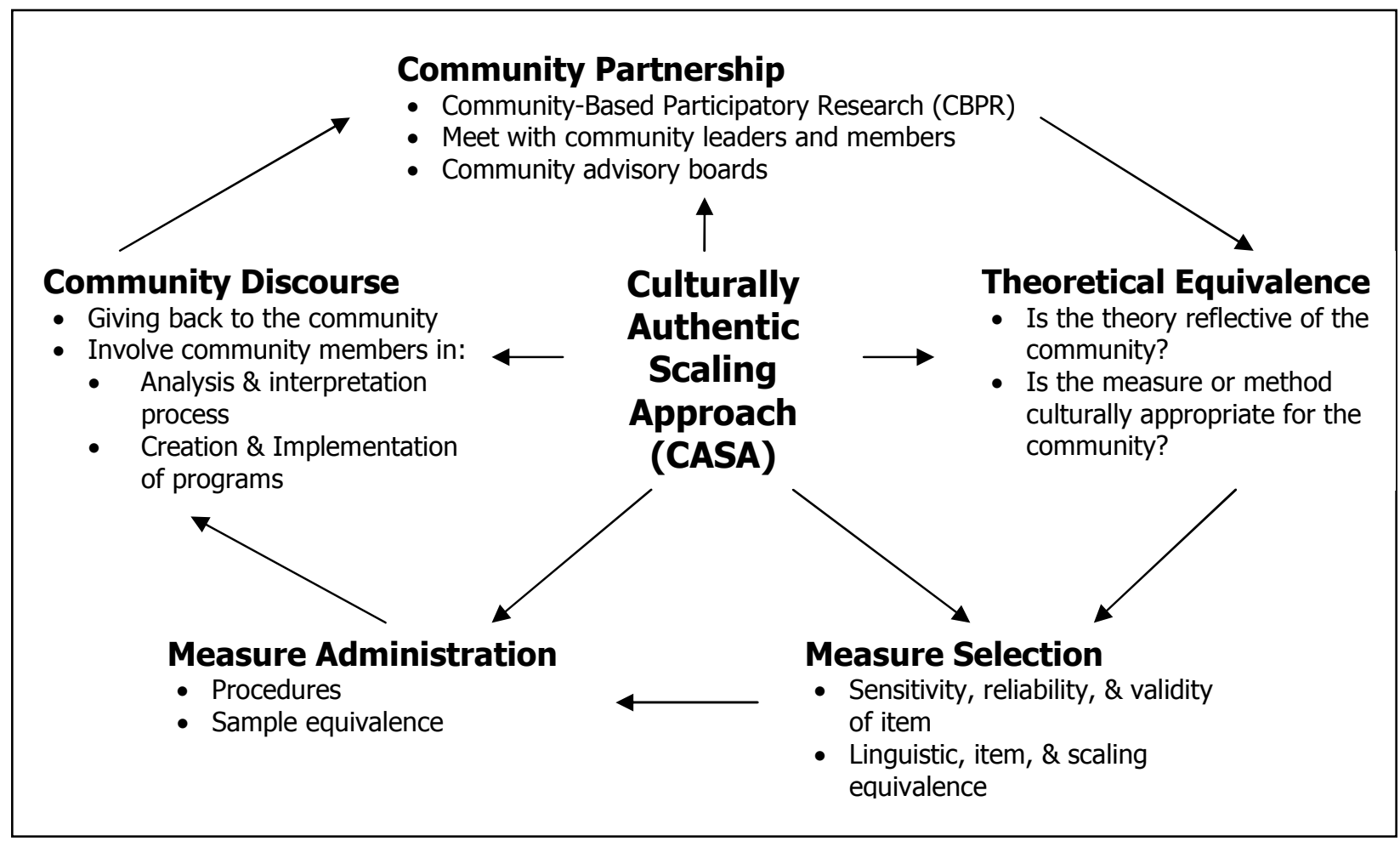


Figure 1 provides an illustration of the specific dimensions of the CASA method (community partnership, theoretical equivalence, measure selection, measure administration, and community discourse). The following sections provide a description of each dimension as well examples from our research illustrating the applicability of this approach.

\section{Community Partnership}

In order to conduct effective cross cultural research with ethnic minority and immigrant youths and families, researchers must first develop a partnership with the community in which they want to work (Mohatt \& Thomas, 2006). Unfortunately, researchers have often engaged in a "flight in and flight out" model of conducting community research, where individuals engage the community in a research program, collect data, and then leave (Triandis, 1992). There is often minimal commitment to becoming familiar with the values, norms, and experiences of the community members which limits the extent to which research is appropriate, accurate and adequately meets the needs of the communities (Mohatt \& Thomas, 2006).

Researchers seeking to include individuals from various cultural backgrounds must develop a clear partnership with these communities prior to the start of research and ensure that a relationship will continue beyond the completion of the current project. Strong ongoing community collaborations are essential for designing and conducting ethical research in ethnic and immigrant communities and are a core component of the CASA method. Although there are several frameworks on effective ways to engage communities in research, Community-Based Participatory Research (CBPR) has recently become the method most frequently employed (O'Fallon, Tyson, \& Dearry, 2000). Community-based participatory research (CBPR) is a methodology that promotes "active community involvement" in the development of research and intervention strategies (Cornwall \& Jewkes, 1995; Israel, Schultz, Parker \& Becker, 1998). An extensive review of CBPR is beyond the scope of this article. Please refer to Freudenberg (1998), Green (1999), Israel and colleagues (1998), and Wallerstein (1999) for additional information.

Example of a community partnership. In order to establish partnerships with the communities in which we wanted to conduct research, we started by scheduling meetings with community leaders to gain their perspective on effective ways of connecting with community members. For example, community leaders suggested that we spend time at local community centers as a way to connect with community members. They also suggested that we attend meetings and events in the community as a way of becoming familiar with the values, norms, experiences, and needs of community members. Once we established connections with community leaders, it was easier for us to reach out to community members. Community members were also more comfortable sharing their experiences and perceptions with us once they knew that community leaders were connected with and trusted us.

Once partnerships were established, we were able to conduct projects and share resources in collaboration with members of the community. For example, members of the community contacted us to connect with experts in particular areas they were interested in learning about and served as resources as we worked on the development of research projects. Researchers working in ethnic minority communities have found community advisory boards to be useful when developing research measures and methodologies (e.g., Brody, Stoneman, Flor, McCrary, Hastings, \& Conyers, 1994). Therefore, as part of establishing a community partnership, we created an advisory board, consisting of members of the community, who provided guidance in establishing culturally relevant research designs and procedures. Overall, establishing a connection with the community before the research begins, allows researchers to first ascertain 
an understanding of the community's needs (from the perspective of community members) and then partner with community members to develop the research program.

\section{Theoretical Equivalence}

After establishing a partnership with the community, it is important to evaluate the cultural relevance of the theoretical framework used to develop the measure for use with the population of interest. It is vital that researchers ensure that the instruments for use in the project are theoretically equivalent across diverse cultural groups. Theoretical equivalence is the extent to which individuals from different cultures maintain universal perceptions of items throughout completion of an instrument (Riordan \& Vandenberg, 1994). In other words, it addresses the extent to which items have the same frame of reference for individuals from different cultures. For example, the word cooking in English may mean a chore or a hobby. The reference point a participant takes will influence how she or he responds to an item that examines the possibility of an analogy between cooking and other activities such as riding a bike (Yu, Keown, \& Jacobs, 1993). The lack of attention to theoretical equivalence in cross-cultural research may lead to erroneous conclusions by researchers.

Researchers rely on two basic approaches for examining the theoretical equivalence of measures; an emic approach (attempts to discover how a system or community looks from the inside) and an etic approach (looks at behavior from the outside for the purpose of comparing cultures) (Gudykunst, 1997; Schaffer \& Riordan, 2003). The type of approach selected by researchers might be influenced by a number of factors (including the purpose and meaning of the project, financial limitations, resources, etc.) and the benefits and drawbacks to each of the approaches (e.g., Beals, Manson, Mitchell, \& Spicer, 2003; Canino, Lewis-Fernández, \& Bravo, 1997). Regardless of the method used, understanding the rationale for the type of approach implemented in a project is critical in improving research with ethnic minority and immigrant populations. Researchers can utilize their community partnerships to help determine which approach is most appropriate for research in their community.

Example of how to assess for theoretical equivalence. Approximately ten years ago, we began a project to understand and examine depression among Black immigrants with a specific focus on Haitians. Given the culture of this ethnic group (Nicolas, DeSilva, Grey, \& Gonzalez-Eastep, 2006) it was imperative that we engaged in a conversation with individual members of the community around the main construct. This was especially necessary since we had clinical data (Nicolas, DeSilva, Subrebost, K., Breland-Noble, Gonzalez-Eastep, Manning, et al., 2007) suggesting that female Haitians experience and understand depression differently than commonly observed and reported in westernized literature. We met with mental health professionals and lay members of the community, in focus groups, and shared with them the existing depression constructs.

Through the focus groups, we were able to develop a new framework for understanding depression among Haitians that was specific to their cultural ideas and beliefs. Research recommends utilizing focus groups when dealing with complex clinical issues among diverse populations (Krueger, 1994). Focus groups are particularly useful for garnering information about the cultural values, beliefs, and traditions of a particular population. Focus groups can also be used to facilitate the assessment and development of culturally sensitive and appropriate measures (Krueger, 1994). Therefore, we also utilized the focus group for guidance around the selection of a measure that was most applicable to their understanding and experience of depression and consistent with the newly developed framework. 


\section{Measure Selection}

Subsequent to resolving issues pertaining to the theoretical equivalence of the constructs being examined, attention needs to be given to the selection of the specific measures for use in the research project, as certain demographic and contextual factors may impact the appropriateness of the measures (Chikudate, 1997). Focusing on and accounting for contextual and demographic factors may reduce the use of measures infused with ethnocentric attitudes, thereby improving cross-cultural research with ethnic minority and immigrant youth populations.

The scope of this paper does not allow for an in-depth examination of measure selection, but two main areas will be reviewed:

(a) sensitivity, reliability, and validity of the measure; and

(b) linguistic, item, and scaling equivalence.

Sensitivity, reliability, and validity of assessment measures. When selecting the assessment measures to use in a research project involving ethnic minority and immigrant youths, it is necessary to consider the sensitivity, reliability, and validity of the questionnaires selected for use in the study.

Sensitivity refers to the extent to which a measure is able to detect differences among participants in a research study (van Widenfelt, Treffers, De Beurs, Siebelink, \& Koudijs, 2005). Sensitivity of a measure is important for a variety of reasons, the most important of which includes being able to detect even small effects of and relationships between the variables in a study (Stevens, 1959).

Reliability refers to the consistency, stability, and repeatability of a questionnaire (Heppner et al., 2007). A reliable assessment instrument does not respond to chance factors or environmental conditions and will yield consistent results if repeated overtime or completed by different people.

Validity refers to the extent to which a questionnaire measures what it claims to measure (Carmines \& Zeller, 1979). In essence, validity refers to the accuracy of a measure. Valid assessment measures yield conclusions and inferences that are appropriate and meaningful. Given that perceptions and experiences may vary across cultures, the reliability and validity of questionnaires may also vary. Therefore, it is essential to test the reliability and validity of each measure with each population with which it is intended to be used.

Linguistic, item, and scaling equivalence. The process of translating instruments across languages can pose specific problems for cross-cultural researchers (Holtzman, 1968). One of the primary issues pertains to the semantics of the instrument, where an item can take on different meanings among cultural groups. Researchers must create multiple versions of the instrument and administer it cross-culturally to ensure that the semantic is consistent across various groups. At the end of the translational process, the meaning of each item in the instrument should be the same for participants from different cultures.

Despite many collaborative back translation procedures with linguists to create uniform versions of instruments, success is rare. For example, in translating a scale into Vietnamese dialect, Small, Rice, Yelland, and Lumley (1999) found that one item on the instrument ("I have been looking forward to things with enjoyment") became partially distorted after the back-translation process. The back-translation resulted in two phrases that were not consistent with the original 
English version (these were, "I have been hoping/expecting to be happy" and "I have been feeling optimistic"). This example shows that even with careful and thorough translations, it is possible that items will take on different meanings and that can significantly affect how the findings are interpreted (Holtzman, 1968).

In addition to semantic issues, specific words on an instrument can unconsciously induce a cognitive or emotional state which can affect the meaning of the items across cultures (Ortega \& Richey, 1998; Ponterotto \& Casas, 1991). Schaffer and Riordan (2003) offer the following phrases as examples of cognitive and emotionally induced items, "What do you think about your supervisor?" and "How do you feel about your supervisor?" Although the meaning of these two questions is similar, the former has a cognitive orientation while the latter has an affective one. It is unclear how these factors affect the translation of items into different languages and whether an affective item in one language elicits the same response in another translation. Given the linguistic and semantic issues which may arise when using scales cross-culturally, every attempt should be made to test a new or newly translated instrument with a focus group prior to implementing the measure in a large project (Krueger, 1994).

The majority of instruments in developmental research utilize a Likert scale, yet research suggests that the Likert scale may be perceived and interpreted differently by individuals from various cultures (Riordan \& Vandenberg, 1994). In particular, non-Western cultures have limited exposure to a Likert-response format and this can lead to erroneous results. Research has consistently shown, for instance, that people from collectivist cultures are more likely to use the middle range/neutral or undecided category of a Likert scale compared to individuals from individualist societies (Triandis, 1994). In addition, researchers have found that some participants will complete an instrument out of a sense of duty, whether or not they agree with the items or feel that it reflects their true feelings (Javeline, 1999; Trimble \& Mohatt, 2006).

Genuine cultural differences should lead to varying response patterns in individuals, not a misapplication of scales across cultures. Two of the most common methods employed by researchers to deal with issues of scale equivalence are covariance structure analysis (CSA, e.g., Cheung \& Rensvold, 1999; Riordan \& Vandenberg, 1994; Ryan et al., 1999; Yang, Chen, Choi, \& Zou, 2000) and item response theory (IRT, e.g., Ellis, Becker, \& Kimmel, 1993; Hambleton \& Kanjee, 1995; Hulin \& Mayer, 1985; Ryan, Horvath, Ployhart, Schmitt, \& Slade, 2000).

Example of measure selection. In our research design meetings with Haitian community members and leaders, we learned that Haitians are not familiar with standardized measures and thus might not be at ease using them. As a result, we selected the top measures in the field and held several meetings with Haitian professionals (e.g., health care providers, religious leaders, and political leaders) and community members to jointly evaluate the constructs and items in these measures to determine if they are appropriate to use with Haitians. We administered the measures that individuals felt might best represent the cultural beliefs of Haitians to a convenience sample of individuals (i.e., a pilot group). We then evaluated them through a rigorous method consisting of statistical analysis and focus group meetings with the participants who completed the measure. Although a small sample $(n=25)$ completed the measure and a high reliability coefficient (alpha $=.86$ ) was obtained, item analysis and our individual meetings with the pilot group participants yielded different results. For example, while the participants answered some of the questions on the depression measure, a number of items were left unanswered. Meetings with the pilot group participants revealed that they left many of the items unanswered because they were not meaningful to them. 
Iota Reliability Statistic

Given the inconsistent findings between the reliability coefficient, the item analysis, and focus group discussions, we have since utilized the Iota reliability statistic (Helms \& Nicolas, 2008) when selecting measures to use in our cross-cultural research. Traditional measures of reliability examine the extent to which items measure a particular construct consistently for a particular sample (e.g., Cronbach's Alpha and Cohen's Kappa). Unfortunately, these measures are not able to provide information regarding the extent to which a scale consistently measures a particular construct for an individual (Helms, Henze, Sass, \& Mifsud, 2006). Therefore, high reliability statistics among a particular population may report nothing more than the fact that the measure is consistently measuring something inconsistently for a particular group of people. Iota reliability is a reliability test statistic developed by Helms and Nicolas (2008), which accounts for variability in responses for any given participant.

The statistic allows for the calculation of new response scores for participants (accounting for variability in their individual responses). Iota coefficients provide numerical indices of the extent to which individual responders, rather than a sample of responders, consistently endorse a set of items intended to assess the same construct (e.g., depression). Response variability among an individual responder is important because that can help to determine whether a particular construct is meaningful for an individual. For example, if an individual does not consistently respond to items that are supposed to measure a particular construct, it is possible (and maybe even probable) that those items are not measuring a meaningful construct for that individual. If the items are consistently not meaningful for each of the individuals in a given sample, a traditional reliability statistic may report high reliability for a scale that, in fact, is not reliable (or consistent) among the individuals responding to the measure.

\section{Administration of Measure}

Subsequent to selecting measures that are culturally appropriate for the participants in the research project, researchers should take appropriate steps to ensure that the administration of the measures is culturally sensitive. In particular, the procedures used to collect data must be clearly delineated and consistent across cultural groups in order to detect genuine cultural differences, as opposed to variations in response patterns due to procedural differences. The following is a review of two of the primary administration issues, sample equivalence and procedure, that should be considered when conducting sound cross-cultural research.

Sample equivalence. When conducting research using different samples, it is customary to make every effort to match the samples on potentially relevant demographic characteristics. As many characteristics as possible are matched in order to effectively rule out variation between groups that are not related to manipulation of the independent variable (Van de Vijver \& Leung, 1997). Therefore, when designing cross-cultural research projects, researchers must pay close attention to similarities and differences between samples on dimensions other than the ones studied. For example, in a study of immigrants' mental health, levels of acculturation, migration patterns, number of residence years in the host country, and connection with home country are factors that may significantly contribute to the observed differences on mental health outcomes of the participants (Schaffer \& Riordan, 2003). Controlling for these factors in research design ensures that the results obtained can be accurately attributed to hypothesized cultural differences and not other individual factors.

In addition to individual differences among the participants, there are differences across samples with regard to social context (e.g., neighborhood or organizational environment) that need to be examined. For example, an ethnic minority adolescent's experience in his or her 
neighborhood can significantly contribute to the values, attitudes, and experiences reported, thereby contributing to variation between samples (Beldona, Inkpen, \& Phatak, 1998; Bui \& Takeuchi, 1992). Going beyond micro-level factors (e.g., demographic variables), to macro-level determinants (e.g., neighborhood climate) is essential to conducting competent cross-cultural research.

When selecting measures to use in cross-cultural research, it is imperative that sample differences relating to individual experiences with the style of the measures be considered and accounted for as experience may differ across cultures (Arthur \& Bennett, 1995; Geletkanycz, 1997). For example, completing surveys and standardized instruments is a process most individuals in Westernized countries are exposed to by the 3rd grade. Thus, participants with extensive exposure to and experience with this testing format might be more familiar and comfortable with completing paper-pencil instruments compared to individuals with limited exposure to such testing methods (Lonner, 1990). Improving research among ethnic minority and immigrant populations demands that investigators examine individuals' comfort and familiarity with the format of the assessment in order to ensure that differences in scores are indeed a function of culture and not ability to complete the measure (Arthur \& Bennett, 1995; Geletkanycz, 1997).

Procedure. In addition to ensuring sample equivalence, it is important to attend to the procedure used to administer research instruments. There are three factors particularly relevant to this endeavor. First, when conducting research with ethnic minority youths, it is imperative that data collection procedures are consistent across the samples. For example, if the research questions are read to participants in one community or cultural group due to literacy issues, then they must be read to all participants involved in the project. Using an equivalent procedure across different cultural groups ensures the reliability and validity of the measures and study (Ortega \& Richey, 1998).

Second, the timing of data collection is another important consideration in the administration of instruments across cultures. Specifically, researchers should ensure that data is collected from all cultures at the same time or within a reasonable time span (Sekaran \& Martin, 1982; Yu et al., 1993) in order to avoid a cohort effect that must be taken into account during the analysis of the data (Roberts \& Boyacigiller, 1984; Roberts, Hulin, \& Rousseau, 1978).

Finally, attending to levels off rapport between researchers and participants is necessary when administering instruments in a cross-culturally competent manner (Anastasi, 1988). Van de Vijver \& Leung (1997) found that when ethnic minority participants were not comfortable with the researchers, they rush through surveys in an effort to avoid further contact with researchers and this may impact the accuracy of the data collected.

Example of measure administration. When conducting cross-cultural research in the Haitian community, there were several steps utilized to ensure that we administered the measures in a way that allowed us to detect cultural differences among the relevant constructs and not differences in other individual or contextual factors. First, we were quite deliberate in our sampling-making sure to collect an equal number of Haitian immigrants (born in Haiti and immigrated to the United States) and Haitian Americans (parents were born in Haiti, but the participant was born in America). We also were cautious to meet with a fairly equal number of participants from community centers, churches, and residencies. Additionally, we designed a demographic form that addressed many of the individual and contextual variables important to understanding ethnic minority and immigrant populations (e.g., birth country, age came to the 
United States; languages spoken, etc.). Having information regarding these factors, allowed us to isolate the variables of interest when running our analyses.

When designing our research project, we also created an interview protocol that our trained research team members were required to follow when meeting with each participant. The protocol provided scripts that interviewers were required to read to the participants and clearly documented the procedure for administering each of the measures. In addition to having a protocol to follow, the interviewers went through several rigorous training sessions where they conducted mock interviews to become familiar and comfortable with the interview procedures. As part of the training sessions, interviewers were educated about conducting ethical and culturally sensitive research with ethnic minorities. For example, interviewers were required to read several articles published by leading scholars in the field of multicultural research (e.g., Fisher \& Ragsdale, 2006; Helms, Henze, Mascher, \& Satiani, 2005; McIntyre, 1997). The combination of providing an interview protocol as well as training sessions helped to increase the likelihood that equivalent procedures were used for each of the participants.

As part of the interview protocol, interviewers were required to spend time getting to know the interviewees in order to establish good rapport with them. The measures were also administered in a very specific order with the more personal measures (e.g., depression measure) toward the end of the interview. This allowed time for the interviewer and interviewee to form a connection prior to administering the more personal measures. Interviewers were also trained to provide time for participants who wanted to move through the interview slowly-telling stories connected to the research questions. As a result, some of the interviews lasted one hour while others lasted over three hours. Importantly, however, the participants were afforded the time necessary to feel comfortable responding to the research questions.

\section{Community Discourse}

After collecting all of the necessary information from community members (e.g., via the scales that were selected for the research project), it is appropriate that the academic community give back to the ethnic and immigrant communities, who shared their personal stories and experiences, through the establishment of programs designed to support and encourage positive development. Thus, in conducting cross cultural research, it is imperative that researchers involve community members in the interpretation of the results, discussing next steps for the community and assisting the community in developing and implementing programs based on their needs.

Similar to the first step of developing a community partnership, community discourse is grounded in the CBPR approach. It emphasizes connecting with community members not solely as subjects but as partners in addressing the needs of the community. Through such partnership, community members are involved in the initial steps of the research and projects are generated based on feedback from the community partners. This process ensures that research provides immediate benefits to the community (Chopyak, 1999; Israel et al., 1998; O'Fallon et al., 2000). Below is an example of how we bring the project full circle through a community discourse around the findings from the project.

Example of community discourse. As suggested through the CBPR approach, a vital part of conducting community-based research is continued collaboration with the communities subsequent to the completion of the research project. In an effort to accomplish this, we scheduled a "day of dialogue" where we invited all 150 participants from the project as well as 
members of the communities (more than 80 participants and community members attended) to engage in a three hour discussion with us about our research findings. We selected a location that was accessible via public transportation, comfortable and facilitated group discussion (e.g., couches arranged in a circle with food available).

Members of our research team presented preliminary results of the project to the entire group and answered specific questions relating to the data. Subsequently, participants were put into working-groups around specific themes from the project. This provided community members the opportunity to offer feedback around the research process and interpretations of the findings. It also allowed for discussions around ways in which we could continue to support the communities. Through these meetings, members of the community identified specific areas of concern that required immediate attention in the community, including a culturally specific mental health program and academic achievement and mentoring programs for youths. Specific committees where formed consisting of community leaders, community members, and researchers focusing on each of these areas to develop a plan of how to address the concerns. As a result of these meetings, Project Success, a mentoring and academic program for ethnic minority and immigrant youths was developed and implemented.

Finally, we prepared educational materials, free from research and psychology jargon, that the community members could take with them, highlighting the research findings, recommendations for community members based on the findings, lists of resources available to them in their communities (e.g., mental health centers, community centers, educational resources, etc), and our contact information so that they could reach us with additional questions or comments regarding the research.

\section{Summary and Conclusions}

Cross cultural researchers, among others, have acknowledged the increasing need to understand and address the needs of ethnic minority and immigrant youths (Alegria, et al., 2004; Mohatt \& Thomas, 2006; Trimble \& Mohatt, 2006). However, despite their noble intent, there continues to be a paucity of cross-cultural research concerning ethnic minority and immigrant youths. This is especially troubling in light of demographic estimates based on the U.S. Census of 2004 which suggest that ethnic and immigrant minority youths comprise the fastest growing and most diverse segment of the population in the nation (U.S. Census, 2004).

Cultural inadequacy of measures used in research studies plagues the existing literature, compromising the ability of researchers to conduct efficacious cross-cultural research with ethnic minority and immigrant youths (Cauce, Ryan-Finn, \& Grove, 1998). Although several new research methods (Cauce \& Gonzalez, 1993; Lawson \& Swenson, 2006) have been offered to ameliorate these concerns, none provide systemic guidelines to ensure that research is meaningful to the population of interest. Thus, the research field is still in dire need of a culturally appropriate method for conducting research with ethnic minority and immigrant populations.

The CASA method presented in this paper addresses the aforementioned need by providing a five step method that researchers can employ to address the culturally sensitive aspect of measures when endeavoring to conduct competent cross-cultural and cross-ethnic research with ethnic minority and immigrant youths. Specifically, the CASA method recognizes the importance of Community Partnership, Theoretical Equivalence, Measure Selection, Measure 
Administration, and Community Discourse, when designing and conducting research with ethnic minority and immigrant youths.

The method provides guidelines and examples that researchers can utilize in conducting research that is meaningful to the specific ethnic minority and immigrant groups represented in their research.

\section{References}

Alegria, M., Takeuchi, D., Canino, G., Duan, N., Shrout, P., Meng, X., et al. (2004). Considering context, space and culture: The national Latino and Asian American study. International Journal of Methods in Psychiatric Research, 13, 208-220.

Anastasi, A. (1988). Psychologica/testing. New York: Macmillan.

Arthur, W., \& Bennett, W. (1995). The international assignee: The relative importance of factors perceived to contribute to success. Personnel Psychology, 48, 99-114.

Beals, J., Manson, S.M., Mitchell, C.M., \& Spicer, P. (2003). Cultural specificity and comparison in psychiatric epidemiology: Walking the tightrope in American Indian research. Culture, Medicine, and Psychiatry, 27, 259-289.

Beldona, S., Inkpen, A.C., \& Phatak, A. (1998). Are Japanese managers more long-term oriented than United States managers? Management International Review, 38, 239-256.

Brody, G.H., Stoneman, Z., Flor, D., McCrary, C., Hastings, L., \& Conyers, O. (1994). Financial resources, parent psychological functioning, parent co-caregiving, and early adolescent competence in rural two-parent African-American families. Child Development, 65, 590-605.

Bui, K.T., \& Takeuchi, D.T. (1992). Ethnic minority adolescents and the use of community mental health care services. American Journal of Community Psychology, 20, 403-417.

Canino, G., \& Bravo, M. (1994). The adaptation and testing of diagnostic and outcome measures for cross-cultural research. International Review of Psychiatry, 6, 281-286.

Canino, G., Lewis-Fernández, R., \& Bravo, M. (1997). Methodological challenges in cross cultural mental health research. Transcultural Psychiatric Research Review, 34, 163-184.

Carmines, E., \& Zeller, R. (1979). Reliability and validity assessment. Newbury Park: Sage Publications.

Cauce, A.M., \& Gonzales, N. (1993). Slouching towards culturally competent research: Adolescents and families of Color in context. Psychological Study of Ethnic Minority Issues, 72 ), 8-9.

Cauce, A.M., Ryan-Finn, K., \& Grove, K. (1998). Children and adolescents of Color where are you? Methodological challenges to the selection, recruitment, and retention of adolescents of Color in developmental research. In V. McLoyd \& L. Steinberg (Eds.), Research with ethnic 
minority adolescents: Methodological issues and challenges (pp. 147-166). New York: Lawrence Erlbaum Associates.

Cheung, P.C., \& Rensvold, R.B. (1999). Testing factorial invariance across groups: A reconceptualization and proposed new method. Journal of Management, 25, 1-27.

Chikudate, N. (1997). Exploring the life-world of organizations by linguistic oriented phenomenology in sub-cultural analysis of organizations: A comparison between Japanese and U.S. banks. Management International Review, 372), 169-183.

Chopyak, J. (1999). Community-based research: Research for action. The Evaluation Exchange Newsletter, 5(2/3), 14-15.

Cornwall, A., \& Jewkes, J. (1995). What is participatory action research? Social Science Medicine, 41, 1667-1676.

Ellis, B.B., Becker, P., \& Kimmel, H.D. (1993). An item response theory evaluation of an English version of the Trier Personality Inventory (TPI). Journal of Cross-Cultural Psychology, 24, 133-148.

Fisher, C.B., \& Ragsdale, K. (2006). Goodness-of-fit ethics for multicultural research. In J. E. Trimble \& C. B. Fisher (Eds.), The handbook of ethical research with ethnocultural populations \& communities (pp. 3-25). Thousand Oaks: Sage Publications.

Freudenberg, N. (1998). Community-based health education for urban populations: an overview. Health Education Behavioral, 25, 11-23.

Geletkanycz, M.A. (1997). The salience of "culture's consequences": The effects of cultural values on top executive commitment to the status quo. Strategic Management Journal, 18(8), 615-634.

Green, L.W. (1999). Health education's contributions to public health in the twentieth century: A glimpse through health promotion's rear-view mirror. Annual Review of Public Health, 20, 6788.

Gudykunst, W.B. (1997). Cultural variability in communication. Communication Research, 24(4), 327-348.

Hambleton, R.K., \& Kanjee, A. (1995). Increasing the validity of cross-cultural assessments: Use of improved methods for test adaptations. European Journal of Psychological Assessment, 11, 147-157.

Helms, J.E. (2006). Fairness is not validity or cultural bias in racial-group assessment: A quantitative perspective. American Psychologist, 61, 845-859.

Helms, J.E., Henze, K.T., Mascher, J., \& Satiani, A. (2005). Ethical issues when White researchers study ALAN and immigrant people and communities. In J. E. Trimble \& C. B. Fisher (Eds.), The handbook of ethical research with ethnocultural populations \& communities (pp. 299-324). Thousand Oaks: Sage Publications. 
Helms, J.E., Henze, K.T., Sass, T.L., \& Mifsud, V.A. (2006). Treating Cronbach Alpha reliability coefficients as data in counseling research. The Counseling Psychologist, 34, 630-661.

Helms, J.E., \& Nicolas, G. (2008). Iota reliability: Accounting for individual differences when determining the reliability of a measure. Unpublished manuscript.

Heppner, P.P., Wampold, B.E., \& Kivlighan, D.M. (2007). Research design in counseling. New York: Wadsworth Publishing Company.

Holtzman, W.H. (1968). Cross-cultural studies in psychology. International Journal of Psychology, 3(2), 83-91.

Hulin, C.L., \& Mayer, L.J. (1985). Psychometric equivalence of a translation of the Job Descriptive Index into Hebrew. Journal of Applied Psychology, 71, 83-94.

Israel, B., Schultz, A.J., Parker, E A., \& Becker, A.B. (1998). Review of community based research: Assessing partnership approaches to improve public health. Annual Review of Public Health, 19, 173-202.

Javeline, D. (1999). Response effects in polite cultures: A test of acquiescence in Kazakhstan. Public Opinion Quarterly, 63, 1-28

Krueger, R.A. (1994). Focus groups: A practical guide for applied research. Thousand Oaks: Sage Publications.

Lawson, L., \& Swenson, C.C. (2006). Research with vulnerable populations. In V. Lynch (Ed.), Forensic Nursing (pp. 235-248). St. Louis: Elsiever Mosby.

Lonner, W.J. (1990). An overview of cross-cultural testing and assessment. In R. W. Brislin (Ed.), Applied cross-cultural psychology (pp. 56-76). Newbury Park: Sage.

McIntyre, A. (1997). Making meaning of my Whiteness: Exploring racial identity with White teachers. Ithaca: State University of New York Press.

Mezzich, J.E., Kirmayer, L.J., Kleinman, A., Fabrega, J.H., Parron, D.L., Good, B.J., et al. (1999). The place of culture in the DSM-IV. Journal of Nervous and Mental Disease, 187, 457464.

Mohatt, G.V., Thomas, L.R. (2006). "I wonder why would you do it that way?" Ethical dilemmas in doing participatory research with Alaska native communities. In J. E. Trimble \& C. B. Fisher (Eds.), The handbook of ethical research with ethnocultural populations \& communities (pp. 93116). Thousand Oaks: Sage Publications.

Nagayama Hall, G.C. (2001). Psychotherapy research with ethnic minorities: Empirical, ethical, and conceptual issues. Journal of Consulting and Clinical Psychology, 69, 502-510.

Nicolas, G., DeSilva, A., Grey, K., \& Gonzalez-Eastep, D. (2006). Using a Multicultural lens to understand illnesses among Haitians living in America. Journal of Professional Psychology: Research and Practice, 37, 702-707. 
Nicolas, G., DeSilva, A., Subrebost, K., Breland-Noble, A., Gonzalez-Eastep, D., Manning, N., et al. (2007). Expression of depression by Haitian women in the United States: Clinical observations. American Journal of Psychotherapy, 61, 83-98.

O'Fallon, L.R., Tyson, F.L., \& Dearry, A. (2000). Successful models of community-based participatory research: Final report. Research Triangle Park: National Institute of Environmental Health Sciences.

Ortega, D.M., \& Richey, C.A. (1998). Methodological issues in social work research with depressed women of Color. Journal of Social Service Research, 23(3-4), 47-70.

Ponterotto, J.G., \& Casas, J.M. (1991). Handbook of racial/ethnic minority counseling research. Springfield: Charles C. Thomas.

Riordan, C.M., \& Vandenberg, R.J. (1994). A central question in cross-cultural research: Do employees of different cultures interpret work-related measures in an equivalent manner? Journal of Management, 20, 643-671.

Roberts, K.H., \& Boyacigiller, N.A. (1984). Cross-national organizational research: The grasp of the blind men. Research in Organizational Behavior, 6, 423-475.

Roberts, K.H., Hulin, C.L., \& Rousseau, D.M. (1978). Developing an interdisciplinary science of organizations. San Francisco: Jossey-Bass.

Ryan, A.M., Chan, D., Ployhart, R.E., \& Slade, L.A. (1999). Employee attitude surveys in a multinational organization: Considering language and culture in assessing measurement equivalence. Personnel Psychology, 52, 37-58.

Ryan, A.M., Horvath, M., Ployhart, R.E., Schmitt, N., \& Slade, L.A. (2000). Hypothesizing differential item functioning in global employee opinion surveys. Personnel Psychology, 53(3), 531-562.

Schaffer, B.S., \& Riordan, C.M. (2003). A review of cross-cultural methodologies for organizational research: A best-practices approach. Organizational Research Methods, 6(2), 169-215.

Sekaran, U., \& Martin, H.J. (1982). An examination of the psychometric properties of some commonly researched individual differences, job, and organizational variables in two cultures. Journal of International Business Studies, 13(1), 51-65.

Small, R., Rice, P.L., Yelland, J., \& Lumley, J. (1999). Mothers in a new country: The role of culture and communication in Vietnamese, Turkish and Filipino women's experiences of giving birth in Australia. Women \& Health, 28(3), 77-101.

Stevens, S.S. (1959), Measurement. In C. W. Churchman (Ed.), Measurement: Definitions and theories (pp. 18-36). New York: Wiley.

Triandis, H.C. (1992). Cross-cultural research in social psychology. In D. Granberg \& G. Sarup (Eds.), Social judgment and intergroup relationships: Essays in honor of Muzafer Sherif. New York: Springer-Verlag. 
Triandis, H.C. (1994). Cross-cultural industrial and organizational psychology. In H. C. Triandis, M. D. Dunnette, \& L. M. Hough (Eds.), Handbook of industrial and organizational psychology (pp. 103-172). Palo Alto: Consulting Psychologists Press.

Trimble, J.E., \& Mohatt, G.V. (2006). Coda: The virtuous and responsible researcher in another culture. In J. E. Trimble \& C. B. Fisher (Eds.), The handbook of ethical research with ethnocultural populations \& communities (pp. 93-116). Thousand Oaks: Sage Publications.

U.S. Census Bureau. (2004). Population division, population projection branch: Question and answer center. Retrieved October 2006 from www.census.gov/population/www/projections/natdet-D1A.html

Van de Vijver, F., \& Leung, K. (1997). Methods and data analysis for cross-cultural research. Thousand Oaks: Sage.

Van Widenfelt, B.M., Treffers, P.D.A., De Beurs, E., Siebelink, B.M., \& Koudijs, E. (2005). Translation and cross-cultural adaptation of assessment instruments used in psychological research with children and families. Clinical, Child, and Family Psychology Review, 8, 135-147.

Wallerstein, N. (1999). Power between evaluator and community: Research relationships with New Mexico's healthier communities. Social Science Medicine, 49, 39-53.

Yang, N., Chen, C.C., Choi, J., \& Zou, Y. (2000). Sources of work-family conflict: A Sino-U.S. comparison of the effects of work and family demands. Academy of Management Journal, $43(1), 113-123$.

Yu, J.H., Keown, C.F., \& Jacobs, L.W. (1993). Attitude scale methodology: Cross-cultural implications. Journal of International Consumer Marketing, 6(2), 47-64.

\section{Acknowledgements:}

The authors wish to express our deepest gratitude and appreciation to Bridget Hirsch for the time and effort she put forth in developing the diagram of the CASA model. In addition, we want to thank all of the members of the Social Support Research Team at Boston College (Diana Arntz, Bridget Hirsch, Claire Lipton, Elizabeth Pierre, Hayden Prater, Alexis Schmiedigen, Bill Schwartz, and Duk-Hae Sung) for their assistance in developing the CASA model and helping to prepare an earlier draft of this manuscript.

(c) Copyright of Journal of Youth Development Bridging Research and Practice. Content may not be copied or emailed to multiple sites or posted to a listserv without copyright holder's express written permission. However, users may print, download or email articles for individual use. 